\title{
Antioxidant vitamins C, E and coenzyme Q10 vs Dexamethasone: comparisons of their effects in pulmonary contusion model
}

\author{
Mertol Gokce ${ }^{1 *}$, Ozkan Saydam', Volkan Hanci ${ }^{2}$, Murat Can $^{3}$ and Burak Bahadir ${ }^{4}$
}

\begin{abstract}
Background: The goal of our study is to evaluate the effects of antioxidant vitamins (vitamin C and E), Coenzyme Q10 (CoQ10) and dexamethasone (Dxm) in experimental rat models with pulmonary contusion (PC).

Methods: Rats were randomly divided into six groups. Except for the control, all subgroups had a moderate pulmonary contusion. Animals in the group I and group II received intraperitoneal saline, group III received 10mg. kg-1 CoQ10 group IV received 100mg.kg-1 vitamin C, group V received 150mg.kg-1 vitamin E, and group VI received 10mg.kg-1 Dxm. Blood gas analysis, serum nitric oxide $(\mathrm{NO})$ and malondialdehyde (MDA) levels as well as superoxide dismutase (SOD) activity assays, bronchoalveolar lavage (BAL) fluid and histopathological examination were performed.

Results: Administration of $\mathrm{CoQ} 10$ resulted in a significant increase in $\mathrm{PaO} 2$ values compared with the group I $(p=0.004)$. Levels of plasma MDA in group II were significantly higher than those in the group I $(p=0.01)$. Early administration of vitamin C, CoQ10, and Dxm significantly decreased the levels of MDA ( $p=0.01)$. Lung contusion due to blunt trauma significantly decreased SOD activities in rat lung tissue compared with group I ( $p=0.01)$. SOD levels were significantly elevated in animals treated with CoQ10, Vitamin E, or Dxm compared with group II $(p=0.01)$.

Conclusions: In our study, CoQ10, vitamin C, vitamin E and Dxm had a protective effect on the biochemical and histopathological outcome of PC after experimental blunt thorax trauma.
\end{abstract}

\section{Background}

Pulmonary contusion (PC) is the most frequently diagnosed intrathoracic injury related to blunt chest trauma, affecting $17-25 \%$ of adult blunt chest trauma patients $[1,2]$. It is also an independent risk factor for the development of pneumonia, severe clinical acute lung injury (ALI) and acute respiratory distress syndrome (ARDS) [1]. The exact mechanisms of PC due to blunt trauma are not yet understood. It may lead to a variety of pathophysiological alterations including inflammation, increased alveolo-capillary permeability, pulmonary oedema, ventilation/perfusion mismatching, increased intrapulmonary shunting, and a loss of compliance [3-8]. PC is revealed to be related to a progressive inflammatory response mediated

\footnotetext{
* Correspondence: dr.mertol@gmail.com

'Department of Thoracic Surgery, Karaelmas University Medical Faculty, Zonguldak, Turkey

Full list of author information is available at the end of the article
}

by local and systemic immunological alterations [8-10]. Cytokines, reactive oxygen species (ROS), and proteolytic enzymes released from macrophages and leucocytes increase the alveolo- capillary membrane permeability and microvascular leakage [11,12]. Although the standard treatment options for these patients remain largely supportive, such as supplemental oxygen, cardiopulmonary monitoring, analgesia and pulmonary hygiene, there is accumulating support for treating the activation of a secondary inflammatory response [6,8-10]. Early supportive approaches, especially for moderate to severe patients with PC in intensive care units, are very important. To understand and evaluate the inflammatory process, antioxidant-oxidant mechanisms, and the effect of the anti-inflammatory drugs after blunt thorax trauma, many experimental animal trials have been conducted [13-16].

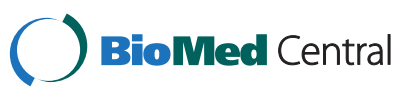


Animal experiments and clinical trials have shown that the administration of coenzyme $\mathrm{Q}_{10}\left(\mathrm{CoQ}_{10}\right)$, which has membrane stabilizing properties and acts as an antioxidant in both mitochondrial and lipid membranes, can inhibit the elevation of serum creatine kinase activity and lipid peroxidation and reduce exercise-induced muscular injuries [17-20]. Certain vitamins, including vitamin $C$ and vitamin $E$, are also suggested to have strong free radical scavenging properties [21,22]. The antioxidant drug Tempol ${ }^{\circledR}$, antioxidant effectivity $\mathrm{N}$-acetyl cystein (NAC) and dexamethasone (Dxm) were also used in experimental PC models [13,16].

The goal of our study was to evaluate the effects of antioxidant vitamins and $\mathrm{CoQ}_{10}$ in experimental rat models with $\mathrm{PC}$ by using isolated blunt thorax trauma and to evaluate the biochemical and histopathological effects by comparing the effects of these antioxidants with the potent anti-inflammatory agent dexamethasone.

\section{Methods \\ Animals}

After the study was approved by the Animal Ethics Committee of Zonguldak Karaelmas University (ZKU) Medical School, 42 adult male Wistar-Albino rats weighting 450-550 g were randomly divided into six groups. All animals were housed in the ZKU Experimental Animals Research Unit in climate controlled rooms $\left(24 \pm 1^{\circ} \mathrm{C}\right)$ on a $12 \mathrm{~h}$ light-12 $\mathrm{h}$ dark cycle. Food and water were available ad libitum. They were fed with food pellets produced specially for experimental animals. Experiments were conducted according to the guiding principles for the care and use of laboratory animals (NIH publication No. 85-23, revised 1985).

\section{Blunt chest trauma model}

Lung contusion was induced using the model of isolated bilateral lung contusion described by Raghavendran et al. [14]. A hollow cylindrical weight (400 g) was dropped from a definite height $(50 \mathrm{~cm})$; it was encased in a vertical stainless steel tube that was positioned on a Lexon platform. This device was then suspended on Teflon guides in order to minimize friction and facilitate energy transfer. The platform was attached to a plastic protective shield that was in direct contact with the lateral aspect of the rat. This precordial shield was designed to protect the heart form contusion and thus directed the impact energy to the chest wall of the rats bilaterally. The impact energy created via this mechanism was calculated by using the equation $\mathrm{E}=\mathrm{mgh}$ [E: energy; g: gravity $(9.8 \mathrm{~m} / \mathrm{s} 2)$; h: height form the platform $(50 \mathrm{~cm}) ; \mathrm{m}$ : mass of the cylindrical weight $(0.40 \mathrm{~kg})]$. The total energy transferred to the chest wall of the rats was calculated as $1.96 \mathrm{~J}$.

\section{Experimental protocol}

Animals were randomly allocated into six groups: group I (Control, $\mathrm{n}=7$ ), group II (Sham $=$ Contusion, $\mathrm{n}=7$ ), group III (Contusion $+\mathrm{CoQ}_{10}, \mathrm{n}=7$ ), group IV (Contusion + vitamin $C, n=7)$, group $V($ Contusion + vitamin $E$, $\mathrm{n}=7$ ) and group VI (Contusion + Dxm, $\mathrm{n}=7$ ). The rats were anesthetized with an intraperitoneal injection of $100 \mathrm{mg} \cdot \mathrm{kg}^{-1}$ ketamine $\mathrm{HCl}$ (50 mg.ml ${ }^{-1}$, Ketalar ${ }^{\circledR}$, Turkey). Blunt chest trauma was then performed. Analgesia was provided by morphine sulphate $\left(0.05 \mathrm{mg} \cdot \mathrm{kg}^{-1}\right)$ administered intraperitoneally. Following the procedure, all subgroups were transferred to their cages. Rats were checked by observing breathing, nose bleeding, respiratory movements and cardiac rhythm. After $45 \mathrm{~min}$. of observation, animals in groups I and II received intraperitoneal saline, group III was given 10 mg.kg ${ }^{-1} \mathrm{CoQ}_{10}$, group IV was given $100 \mathrm{mg} . \mathrm{kg}^{-1}$ vitamin $\mathrm{C}$, group $\mathrm{V}$ was given $150 \mathrm{mg} \cdot \mathrm{kg}^{-1}$ vitamin $\mathrm{E}$, and group VI was given $10 \mathrm{mg} \cdot \mathrm{kg}^{-1} \mathrm{Dxm}$.

All subgroups were observed for $6 \mathrm{~h}$ in their cages. Thereafter, midsternotomy was performed on animals in all subgroups. Blood samples were collected from the descending aorta in a heparinized syringe followed by analysis with a blood gas analyzer. After the left main bronchus was clamped, bronchoalveolar lavage (BAL) of the right lung was performed with $2 \mathrm{ml}$ of normal saline through a tracheal cannula. This was repeated three times; in total, $2 \mathrm{ml}$ of lavage fluid was obtained. At the end of the BAL, the right lung was harvested and the upper lobe was fixed in $10 \%$ formaldehyde for histopathological examination; the remaining portion of the lung was stored at $-20^{\circ} \mathrm{C}$ until further analysis.

\section{Arterial blood gas measurements}

Blood samples were collected from the descending aorta in a heparinized syringe during midsternotomy performed $6 \mathrm{~h}$ after blunt trauma. Analysis was performed by a blood gas analyzer (Cobas $221^{\circledR}$; Roche, Mannheim, Germany) to assess and compare the effects of various drugs administered in the early period of blunt injury on pulmonary shunting.

\section{Biochemical assay}

Biochemical parameters were studied in the blood samples; the activity of superoxide dismutase (SOD) and the levels of malondialdehyde (MDA) and nitric oxide (NO) were analyzed. High performance liquid chromatographic analysis was performed with an isocratic method using a Shimadzu HPLC system (Kyoto, Japan) and a commercial MDA kit (Immundiagnostik AG, Bensheim, Germany). Total SOD activity was determined according to the method from Sun et al. [23]. The principle of the method is based on the inhibition of nitroblue tetrazolium (NBT) reduction by the xanthine-xanthine oxidase 
system as a superoxide generator. One unit of SOD was defined as the enzyme amount causing 50\% inhibition in the NBT reduction rate. Serum NO levels (nitrite + nitrate) were measured by a spectrophotometer at $545 \mathrm{~nm}$ (Shimadzu, Tokyo, Japan) after conversion of nitrate to nitrite by copperized cadmium granules [24]. Results are expressed $\mu \mathrm{mol} / \mathrm{L}$ for MDA, $\mu \mathrm{mol} / \mathrm{L}$ for nitric oxide and $\mathrm{U} / \mathrm{ml}$ for SOD.

\section{PMNL count in BAL}

One slide for cytologic examination was prepared from each BAL sample and stained with hematoxylin-eosin. Smears were then analyzed by using an image analysis program (Leica QWINPlus v. 3.1.0). Ten microscopic fields at x100 magnification were randomly selected. The polymorphonuclear cellularity was determined as the number of cells per $25000 \mu \mathrm{m}^{2}$.

\section{Histopathological examination}

Lung tissue samples were fixed in $10 \%$ formalin immediately after removal, dehydrated in graded concentrations of ethanol, cleared in xylene and embedded in paraffin. At least eight tissue sections of 5- $\mu \mathrm{m}$ thickness were obtained and then stained with hematoxylin-eosin. The sections were examined under a light microscope by a pathologist in a blinded manner. All histopathological changes were documented in each lung tissue, including intra-alveolar haemorrhage, alveolar oedema, disruption and congestion and leukocyte infiltration. Alveolar oedema and congestion were scored on a scale from 0 to 3 where $0=$ absence of pathology $(<5 \%$ of maximum pathology), $1=$ mild $(<10 \%), 2=$ moderate $(15-20 \%)$, and $3=$ severe (20-25\%). Leukocyte infiltration was evaluated to determinate the severity of inflammation resulting from contusion. Each section was divided into 10 subsections, and leukocytic infiltration was examined in each of the subsections at a magnification of $400 \mathrm{X}$ with the following scale; 0 : no extravascular leukocytes; $1:<10$ leukocytes; 2: 10-45 leukocytes; 3: >45 leukocytes. The average of the numbers was used for comparison [25].

\section{Power analysis}

The primary outcome of this study was the determination of the $\mathrm{PaO}_{2}$ values. Sample size estimation was based on the standard deviation of a similar study performed by Türüt et al. [13].We used the $\mathrm{PaO}_{2}$ values of rats in control conditions $(213.57 \pm 26.34)$ determined by the same study (13). In order to detect a $20 \%$ change in $\mathrm{PaO}_{2}$ with an alpha error of 0.05 and a power of $95 \%$, it was calculated that the sample size should be at least 7 rats per group.

\section{Statistical analysis}

Data are presented as means \pm standard deviation. The Mann Whitney $U$ test was used for statistical analysis. $p<0.05$ was defined as the level of statistical significance. A commercial software package (SPSS 11.5 for Windows, SPSS Science, Chicago, IL) was used for data analysis.

\section{Results}

Of the 42 animals subjected to blunt chest trauma, none of the rats died during the experiment. During the follow up period of contused rats, gross evaluation of the respiratory movements indicated a moderate bradypnea early after the trauma, but when the rats were transferred to the cages and supported with oxygen, respiratory rates reflected similar values compared with the control group. All rats exhibited similar behavior concerning mobilization and activity. Median sternotomy grossly indicated the effect of blunt trauma on the lungs; both lungs showed contused areas with a heterogeneous pattern.

Arterial blood gas analysis was assessed at 6 hours after blunt trauma. Results are shown in Table 1. All $\mathrm{PaO}_{2}$ values decreased significantly in group II as compared with the group I $(p<0.05)$. Administration of vitamin $C$, vitamin $E$ and Dxm resulted in a slight increase in $\mathrm{PaO}_{2}$ values compared with the group II, but the difference was not statistically significant $(p>0.05)$. Administration of $\mathrm{CoQ}_{10}$ resulted in a significant increase in

Table 1 Comparison of blood gas analysis results obtained $6 \mathrm{~h}$ after contusion between the control, sham and drug-administered groups

\begin{tabular}{lccc}
\hline Groups & pH & pO2 & pCO2 \\
\hline Groupl: Control $(\mathbf{n}=\mathbf{7})$ & $7.36 \pm 0.03^{\mathrm{b}}$ & $223.16 \pm 11.67^{\mathrm{b}}$ & $38.84 \pm 2.77^{\mathrm{b}}$ \\
Groupll: Sham $(\mathrm{Cont})(\mathbf{n}=\mathbf{7})$ & $7.26 \pm 0.02^{\mathrm{a}}$ & $87.2750 \pm 9.01^{\mathrm{a}}$ & $57.48 \pm 1.07^{\mathrm{a}}$ \\
Grouplll: Cont $+\mathrm{CoQ}_{10}(\mathbf{n}=\mathbf{7})$ & $7.30 \pm 0.02^{\mathrm{ab}}$ & $106.26 \pm 8.92^{\mathrm{ab}}$ & $48.96 \pm 4.05^{\mathrm{ab}}$ \\
GrouplV: Cont + vit C $(\mathbf{n}=\mathbf{7})$ & $7.31 \pm 0.04^{\mathrm{ab}}$ & $100.38 \pm 6.92^{\mathrm{a}}$ & $47.44 \pm 5.77^{\mathrm{ab}}$ \\
GroupV: Cont + vit E $(\mathbf{n}=\mathbf{7})$ & $7.30 \pm 0.02^{\mathrm{ab}}$ & $99.98 \pm 5.57^{\mathrm{a}}$ & $47.88 \pm 3.57^{\mathrm{ab}}$ \\
GroupVl: Cont + Dxm $(\mathbf{n}=\mathbf{7})$ & $7.30 \pm 0.03^{\mathrm{ab}}$ & $102.60 \pm 7.09^{\mathrm{a}}$ & $49.80 \pm 1.92^{\mathrm{ab}}$ \\
\hline
\end{tabular}

Datas are presented as mean \pm S.D.

Cont: contusion, Dxm: Dexamethasone, vit $C$ : vitamin $C$, vit E: vitamin $E$, CoQ ${ }_{10}$ : Co enzyme $Q_{10}$.

a $p<0.05$ in comparison with control.

${ }^{\mathrm{b}} p<0.05$ in comparison sham animals. 
$\mathrm{PaO}_{2}$ values compared with group II $(p=0.004) . \mathrm{PaCO}_{2}$ levels significantly increased in group II compared with the group I $(p=0.01)$. Compared to group II, $\mathrm{PaCO}_{2}$ levels were significantly decreased in the group III, group IV, group V, and group VI $(p<0.05)$. All $\mathrm{pH}$ values significantly decreased in group II compared with the group I $(p=0.01)$.

$\mathrm{pH}$ values of arterial blood gases in all groups were higher than the group II. $\mathrm{pH}$ values in the group IV $(p=0.03)$, and group III $(p=0.03)$ were significantly higher than the group II. However $\mathrm{pH}$ values of group III, group V and group VI were significantly low compared with the group I $(p<0.05)$.

\section{Biochemical results}

Levels of plasma MDA (Table 2) in group II were significantly higher than those in the group I reflecting the significant lipid peroxidation that occurred with lung contusion after blunt trauma $(p=0.01)$. Early administration of vitamin $\mathrm{C}, \mathrm{CoQ}_{10}$, and Dxm significantly decreased the levels of MDA $(p=0.01)$. No significant differences in MDA values were found between the group V and group II $(p=0.06)$.

In group II, lung contusion due to blunt trauma, significantly decreased SOD activity in rat lung tissue compared with group I $(p=0.01)$. SOD levels were significantly elevated in the group III, group V, and group VI compared with group II $(p=0.01)$. No significant difference in SOD values was found between the group IV and group II $(p=0.06)$. In group II, the level of NO was higher than in the group I $(p=0.01)$. Early treatment with vitamin $C$, vitamin $\mathrm{E}, \mathrm{CoQ}_{10}$ and $\mathrm{Dxm}$ decreased the NO levels significantly $(p=0.01)$.

\section{Neutrophil count in BAL}

Contusion resulted in a significant increase in the neutrophil population $(p=0.003)$. Dxm decreased the neutrophil population significantly in the BAL fluid of contused rats $(p=0.016)$ (Figure 1).

\section{Histopathological results}

Scores of alveolar haemorrhage, oedema and disruption as well as leukocyte infiltration scores were significantly higher in group II compared to the group I $(p=0.001)$ (Table 3). In group III, $\mathrm{CoQ}_{10}$ administration, significantly improved the hemorrhage and oedema scores $(p=0.011)$ and the leukocyte infiltration scores $(p=0.002)$ compared to group II. There were no significant difference in the haemorrhage $(p=0.383)$ and leukocyte infiltration $(p=0.073)$ scores between the group II and group IV. There was no significant difference in the haemorrhage scores $(p=0.209)$, but there was a difference in the leukocyte infiltration scores $(p=0.004)$ between the group II and the group V. In group VI, Dxm administration significantly improved the haemorrhage and oedema scores $(p=0.017)$ as well as the leukocyte infiltration scores $(p=0.002)$ compared to the group II.

When the drug-administered groups were compared, no significant differences were found in haemorrhage and leucocyte infiltration scores $(p>0.05)$.

Microscopic findings in the lung specimens revealed normal lung parenchyma in the group I (Figure 2A). In contrast, rats in the group II had disruption of normal alveolar structure with severe congestion and haemorrhage associated with infiltrating leukocytes (Figure 2B). In the group IV and group $\mathrm{V}$, the lungs of the contused rats exhibited moderate degrees of oedema and congestion (Figure 2C and 2D). Rats in the group VI and group III had significantly less leukocyte infiltration with relatively well- preserved alveolar histology compared to the group II (Figure 2E and 2F).

\section{Discussion}

$\mathrm{PC}$ is the most frequently diagnosed injury due to blunt thorax trauma. Because approximately $1 / 3$ of trauma patients admitted to hospitals have thorax trauma, it is an important cause of mortality and morbidity. About $25 \%$ of the patients require invasive mechanical ventilation $[2,4,5,7,16]$. With the development of possible new pharmacological agents and better resuscitation methods, the need for mechanical ventilation may be decreased and

Table 2 The activites of MDA, SOD and NO in serum

\begin{tabular}{lccc}
\hline Groups & MDA $(\boldsymbol{\mu m o l} / \mathbf{m g}$ prot $)$ & SOD $(\mathbf{U} / \mathbf{m g}$ prot $)$ & NO $(\boldsymbol{\mu m o l} / \mathbf{L})$ \\
\hline Groupl: Control $(\mathbf{n}=\mathbf{7})$ & $1.41 \pm 0.16^{\mathrm{b}}$ & $4.38 \pm 0.52^{\mathrm{b}}$ & $38.59 \pm 3.55^{\mathrm{b}}$ \\
Groupll: Sham $($ Cont $)(\mathbf{n}=\mathbf{7})$ & $2.68 \pm 0.37^{\mathrm{a}}$ & $1.14 \pm 0.49^{\mathrm{a}}$ & $82.61 \pm 8.01^{\mathrm{a}}$ \\
Grouplll: Cont $+\mathrm{CoQ}_{10}(\mathbf{n}=\mathbf{7})$ & $1.67 \pm 0.39^{\mathrm{b}}$ & $2.86 \pm 0.53^{\mathrm{ab}}$ & $51.30 \pm 5.89^{\mathrm{ab}}$ \\
GrouplV: Cont + vit C $(\mathbf{n}=\mathbf{7})$ & $1.71 \pm 0.51^{\mathrm{b}}$ & $\mathbf{2 . 4 8} \pm \mathbf{0 . 6 8 ^ { \mathrm { a } }}$ & $56.36 \pm 5.75^{\mathrm{ab}}$ \\
GroupV: Cont + vit E $(\mathbf{n}=\mathbf{7})$ & $\mathbf{1 . 8 9}$ & $2.53 \pm 0.34^{\mathrm{ab}}$ & $57.61 \pm 2.30^{\mathrm{ab}}$ \\
GroupVl: Cont + Dxm $(\mathbf{n}=\mathbf{7})$ & $1.77 \pm 0.22^{\mathrm{b}}$ & $3.49 \pm 0.25^{\mathrm{ab}}$ & $50.98 \pm 8.53^{\mathrm{ab}}$ \\
\hline
\end{tabular}

Datas are presented as mean \pm S.D.

Cont: contusion, Dxm: Dexamethasone, vit $C$ : vitamin $C$, vit E: vitamin $E$, Co $Q_{10}$ : Co enzyme $Q_{10}$.

${ }^{a} p<0.05$ in comparison with control.

${ }^{\mathrm{b}} p<0.05$ in comparison sham animals. 


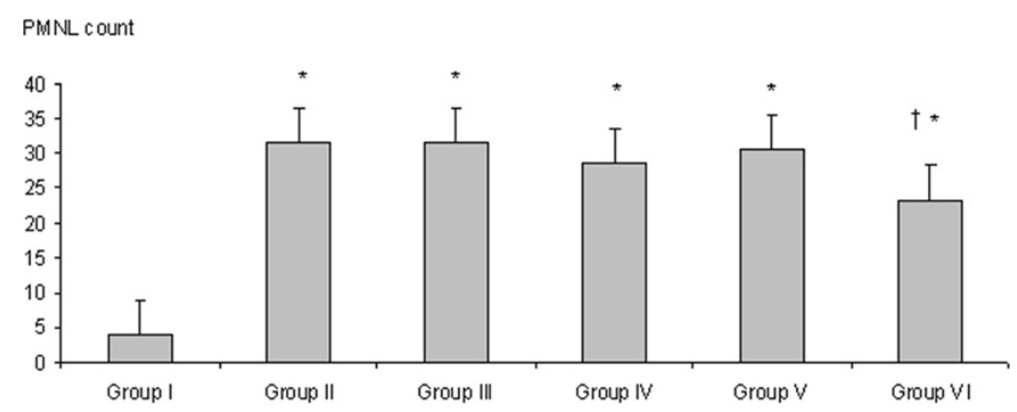

Figure 1 Comparison of BAL fluid neutrophil counts per $\mathrm{mm} 3$ in each group. Contusion resulted in a significant increase in neutrophil population $(p=0.003)$. Contusion-induced neutrophil increase was reduced significantly by Dxm. administration compared to sham group $(p=0.016) . *: p<0.01$ compared Group I, Mann whitney U test. t: $p<0.05$ compared Group II, Mann whitney U test. Group I: control. Group II: contusion (sham). Group III: contusion + $\mathrm{CoQ}_{10}$. Group IV: contusion + vitamin C. Group V: contusion + vitamin E. Group VI: contusion + dexamethasone.

the prognosis of patients with $\mathrm{PC}$ may improve. For studying PC, various blunt thorax trauma models have been previously established. The local and systemic pathophysiological consequences of $\mathrm{PC}$ and the different treatment strategies to minimize the effects of this type of injury have been studied [8,10-13,26-29].

In our study, we used the rat model of lung contusion injury caused by external blunt thoracic trauma as described by Raghavendran et al. [14]. We generated and adapted the rat model mentioned above in order to constitute a moderate PC.

The effects of the PC depend on the extent of the injury. Direct injury causes pulmonary vascular damage with secondary alveolar haemorrhage, and thus the alveoli are poorly perfused. Afterwards, tissue inflammation develops and results in surrounding pulmonary oedema that leads to regional alterations in compliance and airway resistance causing V/Q mismatch. This manifests as a progressive deterioration of pulmonary gas exchange and P/F ratios [7]. Similar previous studies have been conducted to assess the severity of pulmonary shunting and arterial oxygenation in injured rats, revealing severe hypoxia early after induction of contusion. Although it was observed that arterial oxygenation was improved over time, levels persisted at the range of acute lung injury for 4-24 h following contusion [13,30]. In our study, all $\mathrm{PaO}_{2}$ levels were decreased, and all $\mathrm{PaCO}_{2}$ levels were increased significantly at $6 \mathrm{~h}$ after contusion. We detected slight improvement in both $\mathrm{PaO}_{2}$ and $\mathrm{PaCO}_{2}$ levels due to the early administration of antioxidant vitamins (vitamin $\mathrm{C}$, vitamin $\mathrm{E}$ ), $\mathrm{CoQ}_{10}$ and Dxm. PC is associated with a leukocyte-mediated secondary inflammatory response leading to capillary leaking, interstitial oedema and protein extravasation [5,7,10,12]. Strohmaier et al. [11] clearly demonstrated the importance of neutrophil influx in mediating lung injury. Alveolar levels of pro-inflammatory mediators like interleukins and TNF have been shown to rise precipitously after blunt lung injury [16]. It has been elucidated that PC is associated with a progressive inflammatory response mediated by local and systemic immunological alterations [8-13]. Macrophages and neutrophils, which are potentially involved in the inflammatory process, are activated after blunt trauma. Cytokines, reactive oxygen

Table 3 Comparison of leukocyte infiltration and alveolar oedema/congestion scores of the lung tissue in each group

\begin{tabular}{lcc}
\hline Groups & Haemorrhage/oedema/alveolar disruption scores & Leukocyte infiltration \\
\hline Groupl: Control $(\mathbf{n}=\mathbf{7})$ & $0.00 \pm 0.00$ & $0.14 \pm 0.37$ \\
Groupll: Sham $(C o n t)(\mathbf{n}=7)$ & $2.71 \pm 0.48^{\mathrm{a}}$ & $2.85 \pm 0.37^{\mathrm{a}}$ \\
Grouplll: Cont $+\mathrm{CoQ}_{10}(\mathbf{n}=\mathbf{7})$ & $1.71 \pm 0.48^{\mathrm{ab}}$ & $1.71 \pm 0.48^{\mathrm{ab}}$ \\
GrouplV: Cont + vit C $(\mathbf{n}=\mathbf{7})$ & $2.42 \pm 0.53^{\mathrm{acd}}$ & $2.28 \pm 0.48^{\mathrm{acd}}$ \\
GroupV: Cont + vit E $(\mathbf{n}=\mathbf{7})$ & $2.28 \pm 0.48^{\mathrm{a}}$ & $2.00 \pm 0.00^{\mathrm{ab}}$ \\
GroupVl: Cont + Dxm $(\mathbf{n}=\mathbf{7})$ & $1.85 \pm 0.37^{\mathrm{ab}}$ & $1.57 \pm 0.53^{\mathrm{ab}}$ \\
\hline
\end{tabular}

Datas are presented as mean \pm S.D.

Cont: contusion, DXM: Dexamethasone, vit. C: vitamin C, vit. E: vitamin $\mathrm{E}, \mathrm{CoQ}_{10}$ : Co enzyme $\mathrm{Q}_{10}$.

${ }^{a} p<0.05$ in comparison with control.

${ }^{\mathrm{b}} p<0.05$ in comparison sham animals.

c $p<0.05$ in comparison vit $C \&$ CoQ10.

${ }^{d} p<0.05$ in comparison Dxm \& vit $C$. 


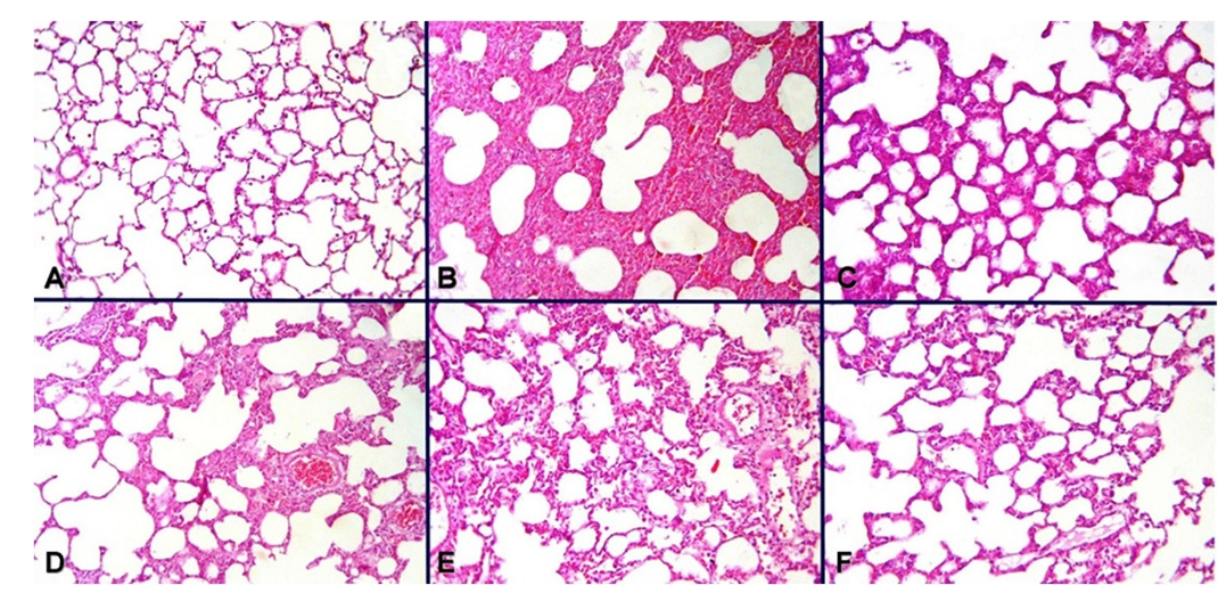

Figure 2 Microphotographs demonstrating (A) control group with normal pulmonary histology; (B) sham group displaying disruption of alveolar structure with extensive congestion, oedema, and hemorrhage; and decreased congestion, and oedema with relative preservation of alveolar histology in the treatment groups: (C) vitamin C, (D) Vitamin E (E), (E) Dxm and (F) CoQ 10 . Best improvement is appreciated in Dxm and $\mathrm{CoQ}_{10}$ group.

metabolites, and proteolytic enzymes are released by both leukocytes and macrophages.

This leads to increased alveolocapillary membrane permeability and microvascular leakage associated with the formation of alveolar oedema fluid, proteolytic and lipolytic enzymes, and reactive oxygens species (ROS) [11]. Alveolar macrophages can produce potent ROS, such as superoxide radicals and, consequently, peroxynitrite. Peroxynitrite can be produced by the reaction of NO with superoxide radicals and represents a highly oxidative species [30]. These ROS in turn are capable of initiating and promoting oxidative damage in the form of lipid peroxidation [18]. Some organs might prevent the damaging effects of the oxidant species through enzymatic and non-enzymatic antioxidant defenses. These defenses include enzymes, such as superoxide dismutase (SOD) and catalase [19]. Malondialdehyde (MDA) is a good indicator of free radical formation, and its elevation shows increased lipid peroxidation due to the effects of these radicals [25]. In our study, MDA levels showed significant increases after contusion, reflecting an indirect finding of oxidative damage. Similarly, NO levels were significantly elevated in the lung tissue. SOD activities were demonstrated to be decreased in the contused rats. These results suggest that oxidants and antioxidants participate in the mechanism of lung injury induced by PC.

The deleterious effects of the free radicals are determined by a delicate balance between the rate of their production and elimination by the different antioxidant systems. Beneficial effects of antioxidant molecules in experimental ALI, blunt trauma and PC models have been established in previous studies. [13,16,31-34]. Maxwell et al. [16] established the positive effects of the antioxidant drug Tempol ${ }^{\circledR}$ in a pig model with unilateral PC. Davis et al. [10] showed that systemic levels of prostacyclin and tromboxane elevate after PC. They also showed attenuation of pulmonary failure by pretreatment with indomethacin due to the effect of prostanoid inhibition. Koksel et al. [31] caused ALI in rats by intravenous administration of oleic acid and showed the positive effects of NAC, which has antioxidant properties. Türüt et al. [13] investigated the biochemical and histopathologic effects of dexamethasone, NAC and aprotinin in PC rat models. They reported that Dxm, NAC and aprotinin treatment have positive effects in bilateral PC, which activates an oxidant-antioxidant cascade.

CoQ10, a component of the mitochondrial electron transport chain, is a strong antioxidant that plays a role in membrane stabilization. Antioxidants inhibit lipid peroxidation by preventing a peroxidation chain reaction and/or picking up reactive oxygen derivatives. Endogenous antioxidants include mitochondrial cytochrome oxidase, SOD, catalase, glutathione peroxidase (GSH-Px), glutathione $\mathrm{S}$-transferase, hydroperoxidase and $\mathrm{CoQ}$. CoQ10 is the only antioxidant that is fat-soluble, synthesized endogenously and is present in tissues in active form (reduced) independently from diet [35]. It has been found in experimental studies that CoQ10 is effective in the treatment of ischemia reperfusion injury. Portakal et al. [36] found that CoQ10 has beneficial effects in the rat liver ischemia-reperfusion damage. Similary, Ostrowski et al. [37] suggested that $\mathrm{CoQ}_{10}$ has beneficial effects in cerebral ischemia. They also reported that $\mathrm{CoQ}_{10}$ reduced the cerebral ischemic lesion diameter in an animal model. Nonetheless, the effectiveness of $\mathrm{CoQ}_{10}$ in a trauma model has not been thoroughly studied. Kerimoglu et al. [38] has demonstrated that $\mathrm{CoQ} 10$ administration was beneficial 
after spinal cord trauma. Tran et al. [39] showed that pretreatment with Tempol ${ }^{\circledR}$ or CoQ10 decreased superoxide production, reduced the infarct size and normalized mitochondrial dysfunction in the gastrocnemius muscle after tourniquet-induced acute ischemia- reperfusion injury in mouse skeletal muscles. However, $\mathrm{CoQ}_{10}$ administration after lung injury in animal models has very rarely been studied. Lim et al. [40] demonstrated that $\mathrm{CoQ}_{10}$ reduced the increase in tumor necrosis factor-alpha (TNF $\alpha$ ) and the injury-induced rise in peak airway pressure following lung injury models in rats. They concluded that $\mathrm{CoQ}_{10}$ may have a protective role in lung injury. They demonstrated that a high-dose of oral $\mathrm{CoQ}_{10}$ was well incorporated into plasma and lung tissue and, to a lesser extent, into the heart. Having shown that oral administration of $\mathrm{CoQ}_{10}$ provided substantial increases in plasma and lung tissue concentrations, the authors tested the benefits of these increases using an in situ lung injury model that incorporated physiological and biochemical measurements used by transplant clinicians to assess the function of the donor lung. The lung ischemia-reperfusion injury (IRI) model demonstrated both increased peak airway pressure, poor gas exchange and increased levels of TNF $\alpha$. In this novel study of the effects of $\mathrm{CoQ}_{10}$ pre-dosing on lung IRI, there is evidence that oral administration of $\mathrm{CoQ}_{10}$ significantly attenuated the rise in cytokine TNF $\alpha$ but not IL-6, MDA and ATP. However, it did not provide sufficient clinical protection against IRI as judged by peak airway pressure and oxygen diffusion gradients [40]. However, there is no study evaluating the role of $\mathrm{CoQ}_{10}$ in a blunt chest trauma model. In our study, comparisons of MDA, SOD and NO levels measured after early administration of $\mathrm{CoQ}_{10}$ in experimental rat models were statistically significant. The serum MDA levels of the group that received $\mathrm{CoQ}_{10}$ were closest to the group I. These findings are similar to the previously published data studying the antioxidant properties of $\mathrm{CoQ}_{10}$ [35-40]. Vitamin $C$ is capable of scavenging oxygen-derived free radicals that are involved in the development or exacerbation of various diseases, including cancer, heart attack, arthritis and stroke [33]. Omeroglu et al. [34] administrated high doses of vitamin $\mathrm{C}$ to rat models with ruptured Achilles tendons and showed that a high dose vitamin $C$ supplementation has positive effects on tendon healing by promoting early angiogenesis and increased collagen synthesis. Cristante et al. [41] demonstrated that vitamin $\mathrm{C}$ reduces the inflammatory response after spinal cord injury in rats. Additionally, Liao et al. [42] showed that early administration of vita$\min C$ is effective for treating spinal cord injury in rats.

In our study, differences in MDA and NO levels after early administration of vitamin $C$ in rats with blunt thorax trauma were found to be statistically significant compared to the group II. This result is consistent with previous studies demonstrating the antioxidant properties of vitamin C in PC $[33,34,41,42]$.

Vitamin $\mathrm{E}$ is the major lipophilic radical-scavenging antioxidant in vivo and protects humans from the oxidative stress mediated by active oxygen and nitrogen species [43].

Koc et al. [44] showed that vitamin E significantly decreased MDA levels, and thus, vitamin E may have a protective effect against spinal cord injury in rats due to its antioxidant properties. In a study comparing the effect of methylprednisolone with or without vitamin $E$ in a rat model of spinal cord damage, the size of the ischemic area was smaller, and adrenaline, noradrenaline, and dopamine levels were lower in the group treated with methylprednisolone and vitamin E [45]. Cristante et al. [41] demonstrated that vitamin E reduces the inflammatory response after spinal cord injury in rats. Wigenstam et al. [46] has also demonstrated that vitamin E reduces acute inflammatory cell influx, suppresses collagen formation in lung tissue and protects against chemically induced lung injury.

In our study, SOD and NO levels in rats who received vitamin $\mathrm{E}$ were statistically significant compared to the group II. This result is concordant with the previously published data describing the antioxidant properties of vitamin E [41-46]. Dexamethasone (Dxm) was also used in experimental PC models [13,16]. Türüt et al. [13] examined the biochemical and histopathologic effects of Dxm in a PC rat model and reported that Dxm has positive effects in bilateral PC through activation of an oxidant-antioxidant cascade.

In our study, MDA, SOD and NO levels in rats who received Dxm were statistically significant compared to the group II. The measured SOD and NO levels are the closest to the group I in our study.

Even though the beneficial effects of corticosteroids have been shown, these drugs have severe adverse effects, such as an increased risk of infection, fluid retention, increased blood pressure, high blood sugar, suppressed adrenal gland hormone production, weight gain, and loss of calcium from bones [47].

However, suitable doses and effective dose ranges of $\mathrm{CoQ}_{10}$ have not yet been identified. According to previous studies, $10 \mathrm{mg} / \mathrm{kg} \mathrm{CoQ} 10$ was commonly administrated within one hour after injury in order to prevent ischemic damage [48]. In our study, we administrated $10 \mathrm{mg} / \mathrm{kg} \mathrm{CoQ} 10$ to rat models immediately after blunt thorax trauma.

Histopathologic examination of lung tissues also supported the potential beneficial effects of the antioxidant vitamins $C$ and $E$ as well as Dxm and $C_{0} Q_{10}$. Parenchymal changes in the contused lungs were characterized by extensive haemorrhage with disruption of the alveoli, 
congestion, and alveolar oedema as well as increased leukocytic infiltration in the alveolar space. Although not statistically significant, vitamin $\mathrm{C}$ and vitamin $\mathrm{E}$ resulted in decreased haemorrhage, oedema and alveolar disruption. In addition, vitamin E significantly decreased leukocytic infiltration. On the other hand, administration of Dxm and $\mathrm{CoQ}_{10}$ subsequent to pulmonary contusion provided significant recovery. The most significant effects on haemorrhage, oedema and alveolar disruption were obtained with $\mathrm{CoQ}_{10}$, and dexamethasone resulted in the greatest decreases in leukocyte infiltration both in pulmonary tissue and BAL fluid. These results emphasize the antioxidant potential of the former and the antiinflammatory property of the latter.

Finally, it appears that free oxygen radicals and lipid peroxidation play a role in $\mathrm{PC}$ after blunt thorax trauma. In our study, $\mathrm{CoQ}_{10}$, vitamin $\mathrm{C}$, vitamin $\mathrm{E}$ and Dxm had protective effects on biochemical and histopathological outcomes of PC after experimental blunt thorax trauma. In particular, we have demonstrated that the best outcome was recorded in rats which were administered $\mathrm{CoQ}_{10}$ with respect to arterial oxygenation, MDA levels and histopathological outcome. Vitamin $\mathrm{C}$ and $\mathrm{E}$ are reliable and easy to administer and have been shown to have significant antioxidant effect. These results support the idea that early treatment with $\mathrm{CoQ}_{10}$, vitamin $\mathrm{C}$, vitamin $\mathrm{E}$, and dexamethasone may yield favorable effects on pulmonary pathophysiologic parameters of blunt thorax trauma patients.

\section{Competing interests}

The author(s) (Gokce M; Saydam O, Hanci V, Can M, Bahadir B) declare that they have no competing interests.

\section{Authors' contributions}

Gokce M and Hanci V designed the research; Gokce M, Saydam O, Can M and Bahadir B performed the research; Hanci V, Can M and Bahadir B analyzed the data; Gokce M, Saydam O and Hanci V wrote the paper. All authors read and approved the final manuscript.

\section{Author details}

'Department of Thoracic Surgery, Karaelmas University Medical Faculty, Zonguldak, Turkey. ${ }^{2}$ Department of Anesthesiology and Intensive Care Medicine, Karaelmas University Medical Faculty, Zonguldak, Turkey. ${ }^{3}$ Department of Biochemical, Karaelmas University Medical Faculty, Zonguldak, Turkey. ${ }^{4}$ Department of Pathology, Karaelmas University Medical Faculty, Zonguldak, Turkey.

Received: 17 February 2012 Accepted: 23 September 2012 Published: 26 September 2012

\section{References}

1. Miller PR, Croce MA, Bee TK, Qaisi WG, Smith CP, Collins GL, Fabian TC: ARDS after pulmonary contusion: accurate measurement of contusion volume identifies high-risk patients. J Trauma 2001, 51:223-228.

2. Cohn SM: Pulmonary contusion: review of the clinical entity. J Trauma 1997, 42:973-979.

3. Cohn SM, Zieg PM: Experimental pulmonary contusion: review of the literature and description of a new porcine model. J Trauma 1996, 41:565-571.
4. Kollmorgen DR, Murray KA, Sullivan JJ, Mone MC, Barton RG: Predictors of mortality in pulmonary contusion. Am J Surg 1994, 168:659-664.

5. Desselle WJ, Greenhaw JJ, Trenthem LL, Fabian TC, Proctor KG: Macrophage cyclooxygenase expression, immunosupression and cardiopulmonary dysfunction after blunt chest trauma. J Trauma 2001, 51:239-252.

6. Kelly ME, Miller PR, Grenhaw JJ, Fabian TC, Proctor KG: Novel resuscitation strategy for pulmonary contusion after severe chest trauma. J Trauma 2003, 55:94-105.

7. Hoth JJ, Stitzel JD, Gayzik FS, Brownlee NA, Miller PR, Yoza BK, Mc Call CE, Meredith JW, Payne RM: The pathogenesis of pulmonary contusion: an open chest model in the rat. J Trauma 2006, 6:32-44.

8. Knöferl MW, Liener UC, Seitz DH, Perl M, Brückner UB, Kinzl L, Gebhard F: Cardiopulmonary, histological and inflammatory alterations after lung contusion in a novel mouse model of blunt chest trauma. Shock 2003, 19:519-525.

9. Klein Y, Cohn SM, Proctor KG: Lung contusion: pathophysiology and management. Curr Opin Anaesthesiol 2002, 15:65-68.

10. Davis KA, Fabian TC, Croce MA, Proctor KG: Prostanoids: early mediators in the secondary injury that develops after unilateral pulmonary contusion. J Trauma 1999, 46:824-832.

11. Strohmaier W, Trupka A, Pfeiler C, Thurnher M, Khakpour Z, Gippnerr-Steppert C, Jochum M, Redl H: Bilateral lavage with diluted surfactant improves lung function after unilateral lung contusion in pigs. Crit Care Med 2005, 33:2286-2293.

12. Perl M, Gebhard F, Bruckner UB, Ayala A, Braumüller S, Büttner C, Kinzl L, Knöferl MW: Pulmonary contusion causes impairment of macrophage and lymphocyte immune functions and increases mortality associated with a subsequent septic challenge. Crit Care Med 2005, 33:1351-1358.

13. Türüt $H$, Ciralik H, Kilinc M, Ozbag D, Imrek SS: Effects of early administration of dexametahasone, $\mathrm{N}$-acetylcysteine and aprotinin on inflammatory and oxidant- antioxidant status after lung contusion in rats. Injury 2009, 40(5):521-527.

14. Raghavendran K, Davidson BA, Helinski JD, Marschke CJ, Manderscheid P, Woytash JA, Notter RH, Knight PR: A rat model for isolated bilateral lung contusion from blunt chest trauma. Anesth Analg 2005, 101(5):1482-1489.

15. Raghavendran K, Notter RH, Davidson BA, Helinski JD, Kunkel SL, Knight PR Lung contusion: inflammatory mechanisms and interaction with other injuries. Shock 2009, 32(2):122-130. Review.

16. Maxwell RA, Gibson JB, Fabian TC, Proctor KG: Effect of a novel antioxidant during resuscitation from severe blunt chest trauma. Shock 2000, 14(6):646-651.

17. Kon M, Kimura F, Akimoto T, Tanabe K, Murase Y, Ikemune S, Kono I: Effect of Coenzyme $Q_{10}$ supplementation on exercise-induced muscular injury of rats. Exerc Immunol Rev 2007, 13:76-88.

18. Zhou S, Zhang Y, Davie A, Marshall-Gradisnik S, Hu H, Wang J, Brushett D: Muscle and plasma coenzyme $Q_{10}$ concentration, aerobic power and exercise economy of healthy men in response to four weeks of supplementation. J Sports Med Phys Fitness 2005, 45:337-346.

19. Mabuchi H, Nohara A, Kobayashi J, Kawashiri MA, Katsuda S, Inazu A, Koizumi J, Hokuriku Lipid Research Group: Effect of $\mathrm{CoQ}_{10}$ supplementation on plasma lipoprotein lipid, $\mathrm{CoQ}_{10}$ and liver and muscle enzyme levels in hypercholesterolemic patients treated with atorvastatin: a randomized double-blind study. Atherosclerosis 2007, 195(2):182-189.

20. Shimomura Y, Suzuki M, Sugiyama S, Hanaki Y, Ozawa T: Protective effect of coenzyme $Q_{10}$ on exercise-induced muscular injury. Biochem Biophys Res Commun 1991, 176(1):349-355.

21. Rose RC: Ascorbic acid metabolism in protection against free radicals: a radiation model. Biochem Biophys Res Commun 1990, 169(2):430-436.

22. Koul A, Bhatia V, Bansal MP: Effect of alpha-tochopherol on pulmonary antioxidant defence system and lipid peroxidation in cigarette smoke inhaling mice. BMC Biochem 2001, 2:14.

23. Sun Y, Oberley LW, Li Y: A simple method for clinical assay of superoxide dismutase. Clin Chem 1988, 34:497-500.

24. Cortas NK, Wakid NW: Determination of inorganic nitrate in serum and urine by a kinetic cadmium-reduction method. Clin Chem 1990, 36:1440-1443.

25. Calikoglu M, Tamer L, Sucu N, Coskun B, Ercan B, Gul A, Calikoglu I, Kanik A: The effects of caffeic acid phenetyl ester on tissue damage in lung after hindlimb ischemia-reperfusion. Pharmacol Res 2003, 48:397-403.

26. Greenbery SM, Frishman WH: Coenzyme Q10: a new drug for myocardial ischemia? Med Clin North Am 1988, 72:243. 
27. Maxwell RA, Gibson JB, Fabian TC, Proctor KG: Resuscitation of severe chest trauma with four different hemoglobin-based oxygen-carrying solutions. J Trauma 2000, 49:200-209.

28. Ischiropulos H, Zhu L, Beckman JS: Peroxynitrite formation from macrophage derived nitric oxide. Arch Biochem Biophys 1992, 298(2):446-451.

29. Wang ND, Stevens MH, Doty DB, Hammond EH: Blunt chest trauma: an experimental model for heart and lung contusion. J Trauma 2003, 54:744-748.

30. Raghavendran K, Davidson BA, Woytash JA, Helinski JD, Marschke CJ, Manderscheid P, Notter RH, Knight PR: The evolution of isolated bilateral lung contusion from blunt chest trauma in rats: cellular and cytokine responses. Shock 2005, 24:132-138.

31. Koksel O, Ozdulger A, Ercil M, Tamer L, Ercan B, Atik U, Cinel L, Cinel I, Kanik A: Effects of $\mathrm{N}$-acetylcysteine on oxidant- antioxidant balance in oleic acidinduced lung injury. Exp Lung Res 2004, 30(6):431-446.

32. Koksel O, Cinel I, Tamer L, Cinel L, Ozdulger A, Kanik A, Ercan B, Oral U: $\mathrm{N}$-Acetylcystein inhibits peroxynitrite- mediated damage in oleic acid-induced lung injury. Pulm Pharmacol Ther 2004, 17:263-270.

33. Tsai PJ, Chen WY, Tzeng SF, Liang WM, Yang CS: Experimental spinal cord injury induced an increase of extracellular ascorbic acid concentration in anesthetized rats: a microdialysis study. Clin Chim Acta 2005, 362(1-2):94-100

34. Omeroğlu S, Peker T, Türközkan N, Omeroğlu H: High-dose vitamin C supplementation accelerates the Achilles tendon healing in healthy rats. Arch Orthop Trauma Surg 2009, 129(2):281-286.

35. Bentinger M, Brismar K, Dallner G: The antioxidant role of coenzyme Q. Mitochondrion 2007 Jun, (Suppl):S41-S50.

36. Portakal $\mathrm{O}$, Inal-Erden M: Effects of pentoxifylline and coenzyme $\mathrm{Q}_{10}$ in hepatic ischemia/reperfusion injury. Clin Biochem 1999, 32(6):461-466.

37. Ostrowski RP: Effect of coenzyme $Q_{10}$ on biochemical and morphological changes in experimental ischemia in the rat brain. Brain Res Bull 2000, 53(4):399-407.

38. Kerimoglu A, Pasaoglu O, Kanbak G, Hanci V, Özdemir F, Atasoy MA: Efficiency of coenzyme $Q_{10}$ at experimental spinal cord injury. Turkish Journal of Trauma \& Emergency Surgery 2007, 13(2):85-93.

39. Tran TP, Tu H, Pipinos II, Muelleman RL, Albadawi H, Li YL: Tourniquetinduced acute ischemia-reperfusion injury in mouse skeletal muscles: Involvement of superoxide. Eur J Pharmacol 2011, 10;650(1):328-334. Epub 2010 Oct 29.

40. Lim HK, Jayaweera S, Calderone A, Pepe S, Rosenfeldt FL, Marasco SF: Protective role of coenzyme $Q_{10}$ in two models of rat lung injury. ANZ J Surg 2010, 80(4):265-270.

41. Cristante AF, Barros Filho TE, Oliveira RP, Marcon RM, Rocha ID, Hanania FR, Daci K: Antioxidative therapy in contusion spinal cord injury. Spinal Cord 2009, 47(6):458-463.

42. Liao JW, Song YM: Preliminary study of the effects of high-dose Vitamin C on acute spinal cord injury in rats. Sichuan Da Xue Xue Bao Yi Xue Ban 2004, 35(6):854-857.

43. Niki E, Noguchi N: Dynamics of antioxidant action of vitamin $\mathrm{E}$. Acc Chem Res 2004, 37:45-51.

44. Koc RK, Akdemir H, Karakücük El, Oktem IS, Menkü A: Effect of methylprednisolone, tirilazad mesylate and vitamin $\mathrm{E}$ on lipid peroxidation after experimental spinal cord injury. Spinal Cord 1999, 37(1):29-32

45. Wigenstam E, Rocksén D, Ekstrand-Hammarström B, Bucht A: Treatment with dexamethasone or liposome-encapsuled vitamin $E$ provides beneficial effects after chemical-induced lung injury. Inhal Toxicol 2009, 21(11):958-964.

46. Daneyemez M: Silicone rubber microangiography of injured acute spinal cord after treatment with methylprednisolone and vitamin $\mathrm{E}$ in rats. Spine 1999, 24:2201-2205.

47. Dujovne CA, Azarnoff DL: Clinical complications of corticosteroid therapy: A selected review. Med Clin North Am 1973, 57(5):1331-42.

48. Yokoyama K, Nakamura $K$, Nakamura $K$, et al: Effect of coenzyme $Q_{10}$ on superoxide production in rats with reperfusion injuries. Scand J Plast Reconstr Surg Hand Surg 1999, 33:1-5.

\section{Submit your next manuscript to BioMed Central and take full advantage of:}

- Convenient online submission

- Thorough peer review

- No space constraints or color figure charges

- Immediate publication on acceptance

- Inclusion in PubMed, CAS, Scopus and Google Scholar

- Research which is freely available for redistribution 